\title{
Impact of Brain Malformations on Neurodevelopmental Outcome in Children with a History of Prenatal Surgery for Open Spina Bifida
}

\author{
David-Alexander Wille ${ }^{a, b, c, d}$ Beth Padden ${ }^{b, c, d, e}$ Ueli Moehrlen $^{b, c, d, f}$ \\ Beatrice Latal $^{b, c, d, g}$ Sonja Schauer ${ }^{b, c, d, f} \quad$ Raimund Kottke $^{b, c, d, h}$ \\ Patrice Grehten ${ }^{b, c, d, h}$ Martin Meulib, c, d, f
}

aDepartment of Pediatric Neurology Kantonsspital Baden, Baden, Switzerland; b Zurich Center for Spina Bifida, University Children's Hospital Zurich, Zurich, Switzerland; 'Spina Bifida Academy, University Children's Hospital and University Hospital Zurich, Zurich, Switzerland; 'Children's Research Center, University Children's Hospital Zurich, Zurich, Switzerland; 'Division of Pediatric Rehabilitation University Children's Hospital Zurich, Zurich, Switzerland; fDivision Fetal Surgery, Department of Pediatric Surgery, University Children's Hospital Zurich, Zurich, Switzerland; ${ }^{9}$ Child Development Center, University Children's Hospital Zurich, Zurich, Switzerland; hepartment of Pediatric Radiology, University Children's Hospital Zurich, Zurich, Switzerland

\section{Keywords}

Spina bifida · Fetal · Prenatal surgery · Brain malformations · Development

\begin{abstract}
Introduction: This retrospective study investigates brain malformations and their impact on neurodevelopmental outcome in children after prenatal surgery for spina bifida (SB). Methods: Sixty-one patients were included. On neonatal MRI, SB-associated brain malformations were assessed. Ventricular size, ventriculo-peritoneal shunt (VPS), and endoscopic third ventriculostomy (ETV) were also documented. Neurodevelopment was assessed with the Bayley-III and correlated with brain malformations, ventricular size, and VPS/ETV placement. Results: Chiari II malformation was detected in all patients. Corpus callosum (CC) abnormality was noted in $40 \%$, heterotopies in 35\%, and cerebellar parenchymal defects in $11 \% .96 \%$ had ventriculomegaly; in $46 \%$, VPS/ ETV was performed. Cognitive and language testing yielded results in the low-average range (Bayley-III: Cognitive Composite Score 93.6, Language Composite Score 89.7), motor testing was below average (Motor Composite Score 77.4). CC
\end{abstract}

karger@karger.com www.karger.com/fdt

Karger $\stackrel{\text { ' }}{5}$

GOPEN ACCESS
(C) 2021 The Author(s)

Published by S. Karger AG, Basel

This is an Open Access article licensed under the Creative Commons Attribution-NonCommercial-4.0 International License (CC BY-NC) (http://www.karger.com/Services/OpenAccessLicense), applicable to the online version of the article only. Usage and distribution for commercial purposes requires written permission. abnormalities, heterotopies, and cerebellar defects were not associated with poorer Bayley-III scores, whereas patients with severe ventriculomegaly performed poorer in all subtests, significantly so for the language composite score. Patients requiring intervention for hydrocephalus had significantly lower scores in motor testing. Discussion/Conclusion: Additional brain malformations in open SB do not seem to have an impact on cognitive function at 2 years of age. Severe ventriculomegaly is a risk factor for poorer cognitive outcome; hydrocephalus surgery adds an additional risk for delayed motor function. @ 2021 The Author(s)

Published by S. Karger AG, Basel

\section{Introduction}

Open spina bifida (SB), which includes myelomeningocele and myeloschisis, has an incidence of 3.4 per 10,000 live births and is one of the most common and devastating congenital anomalies of the central nervous

Patrice Grehten and Martin Meuli shared last authorship.
Correspondence to:

David-Alexander Wille, david.wille@ ksb.ch 
system [1]. Failure of primary neurulation leads to open exposure of the neural placode through a defect in the vertebral column and overlying soft tissues. The severity of the various neurologic dysfunctions (cerebral, spinal, and peripheral) is correlated with level and extent of the spinal defect and with a cluster of cerebral anomalies known as Chiari II malformation (CM II) [1-4]. CM II is detected in $44-100 \%$ of patients with SB [5-7]. It includes hindbrain herniation $(\mathrm{HH})$, brain stem abnormalities, and a small, crowded posterior fossa and is associated with additional malformations of the fore, mid-, and hindbrain $[1,8]$. Typically, these include structural anomalies of the corpus callosum (CC), disorders of cortical development, especially periventricular heterotypies and cerebellar defects. Taken together, CM II was therefore classified as a pancerebral malformation [8-10].

One important consequence of CM II is ventriculomegaly, an almost constant finding in fetal and newborn ultrasound and/or MRI. Hydrocephalus, the correlating clinical entity of ventriculomegaly, afflicts about $90 \%$ of patients with open SB and requires CSF diversion in nearly all patients $[1,9]$. Notably, the need for CSF diversion in patients who underwent fetal SB repair was markedly reduced [1]. In our cohort, the shunt rate was 37\% [11]. Outcomes of patients with fetal ventriculomegaly are well documented. In SB patients with hydrocephalus, cognitive impairment is more severe than in patients without hydrocephalus, with particularly poor performance in executive functions [12].

The theory generally consented to today regarding the disastrous and irreversible neurological deficit associated with SB is the "2-hit-hypothesis" formulated by Heffez et al. [13], Hutchins et al. [14], and Meuli et al. [15] in the midnineties, according to which the secondary, in utero acquired, damage (=second, "extrinsic," hit) to the pathologically exposed spinal cord tissue seems to be a more important pathogenic factor than the failure of neural tube closure (first, "intrinsic," hit) itself. Novel fetal sheep models, created by Meuli et al. [16, 17], and evidence from aborted human fetuses with open SB $[14,15]$ strongly support the pathogenetic view of progressive neural tissue destruction and loss of function with ongoing gestation and are also compellingly indicative that timely in utero SB coverage spares function at birth [18]. Importantly, in a mouse model of a naturally occurring open SB, findings were perfectly consistent with the 2-hit-pathogenesis $[19,20]$.

The above mentioned evidence leads to the first open human prenatal myelomeningocele repair performed in Philadelphia by Adzick et al. [21] in the year 1997. Subsequent studies showed largely reversible $\mathrm{HH}$ after pre- natal SB repair and a markedly reduced shunt rate and improved mobility compared with postnatal repair [1, 22-24]. In 2011, the MOMS trial compared prenatal SB repair with the standard postnatal repair and showed that prenatal intervention significantly improved outcomes in various domains, but was not free of maternal and fetal risks [1]. Yet, the trial was stopped for higher efficacy of prenatal over postnatal surgery [1]. Thus, prenatal surgery has become a standard treatment option for selected patients. In 2010, the Zurich Center for Fetal Diagnosis and Therapy (www.swissfetus.ch) started a fetal surgery program [25]. To date, the center has performed over 150 open fetal MMC repairs [11]. Our outcome results are comparable or partly even better when compared to MOMS [26]. The main goal of the present study was to identify SB-associated brain malformations in a cohort of consecutive SB patients undergoing fetal surgery, particularly focusing on CC abnormalities, heterotopies, additional cerebellar defects beside the classical CM II, as well as to look at ventriculomegaly and to determine whether these pathologies have a negative impact on cognitive, language, and motor development in early life.

\section{Patients and Methods}

Between December 2010 and July 2017, 61 consecutive patients underwent open prenatal SB repair at the Zurich Center for Fetal Diagnosis and Therapy (www.swissfetus.ch), Switzerland. The MOMS inclusion and exclusion criteria were applied with some modifications (the criteria maternal BMI, hypertension, psychosocial background as well as certain fetal anomalies such as irrelevant kidney anomalies and minor genetic anomalies were evaluated on an individual basis) [1]. This single-center retrospective analysis was performed on brain malformations, cognitive, and motor outcome parameters of patients with SB. Baseline characteristics, sex, gestational age at fetal surgery and birth, and birth weight were collected in a REDCap database.

All neonates underwent MRI of the neuroaxis using a 1.5 or 3-T scanner (Discovery MR450 or MR750, GE Healthcare, Waukesha, WI, USA) within the first 14 days of life. None had ventriculoperitoneal shunt (VPS) or endoscopic third ventriculostomy (ETV) at the time of imaging. Age at VPS and ETV intervention was documented.

Cranial MRI findings were analyzed by an experienced pediatric neuroradiologist for CM II, ventricular size, CC abnormalities, presence, number, and location of heterotopies, presence and extent of $\mathrm{HH}$, cerebellar diameter, and presence of cerebellar parenchymal defects. CM II was considered present when the following criteria were met: downward herniation of the cerebellum, downward displacement of medulla, pons, and fourth ventricle, medullary kinking, abnormally shaped fourth ventricle, hypoplastic tentorium, and beaking of the quadrigeminal plate $[1,6,8,27] . \mathrm{HH}$ was defined as a transforaminal herniation of brainstem and cer- 


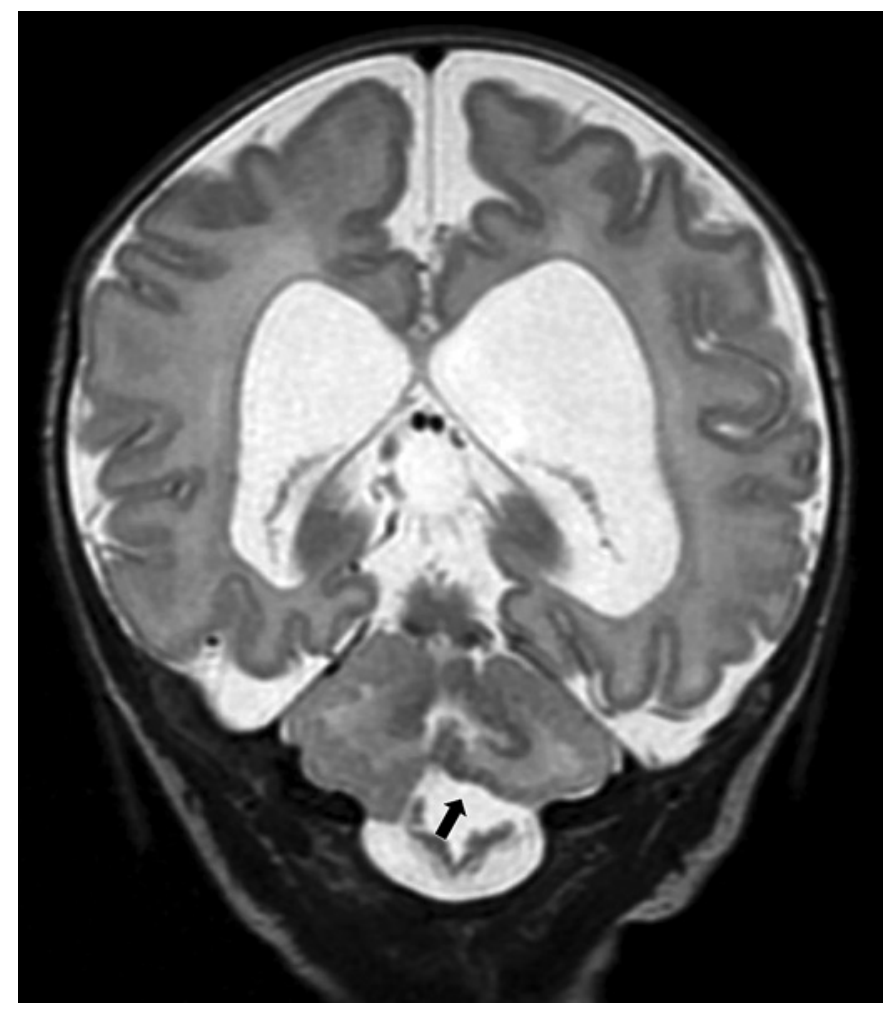

Fig. 1. Dysplasia of the lower left cerebellar hemisphere (T2 coronary imaging).

ebellum lower than the foramen magnum into the cervical spinal canal. Ventricular size was assessed by measurement of the lateral ventricular diameter on a coronal slice at the level of the ventricular atrium. Mild ventriculomegaly was defined as $10.1-15 \mathrm{~mm}$, moderate as 15.1-20 mm, moderate-severe $20.1-25 \mathrm{~mm}$, and severe larger than $25 \mathrm{~mm}$ [28]. Regarding the FOHR index, ventriculomegaly was defined as a ratio larger than 0.44 [29] (Even though, theoretically, a comparison of postnatal with prenatal data regarding CC anomalies, heterotypies, and cerebellar defects, would be interesting, we have not included such data, since these pathologies are usually not yet detectable around midgestation, when our imaging was done).

Development was assessed by experienced pediatricians of our Child Development Center using the Bayley Scales of Infant and Toddler Development (Bayley-III) at the adjusted age of 24 months. The Bayley-III is used for children from 1 to 42 months of age and provides 3 scores: Cognitive Composite Score (CCS), Language Composite Score (LCS), and Motor Composite Score (MCS). Each score has a mean of 100 and a standard deviation (SD) of \pm 15 [30].

Statistical analyses were performed by the University of Zurich, Switzerland. Descriptive statistics included mean and SD for continuous variables and numbers and percentages of total for categorical and ordinal variables.

Bayley-III scores were compared between children with and without VPS/ETV. The comparison used box plots, $t$ tests, and estimation of between-group difference with $95 \%$ confidence intervals.

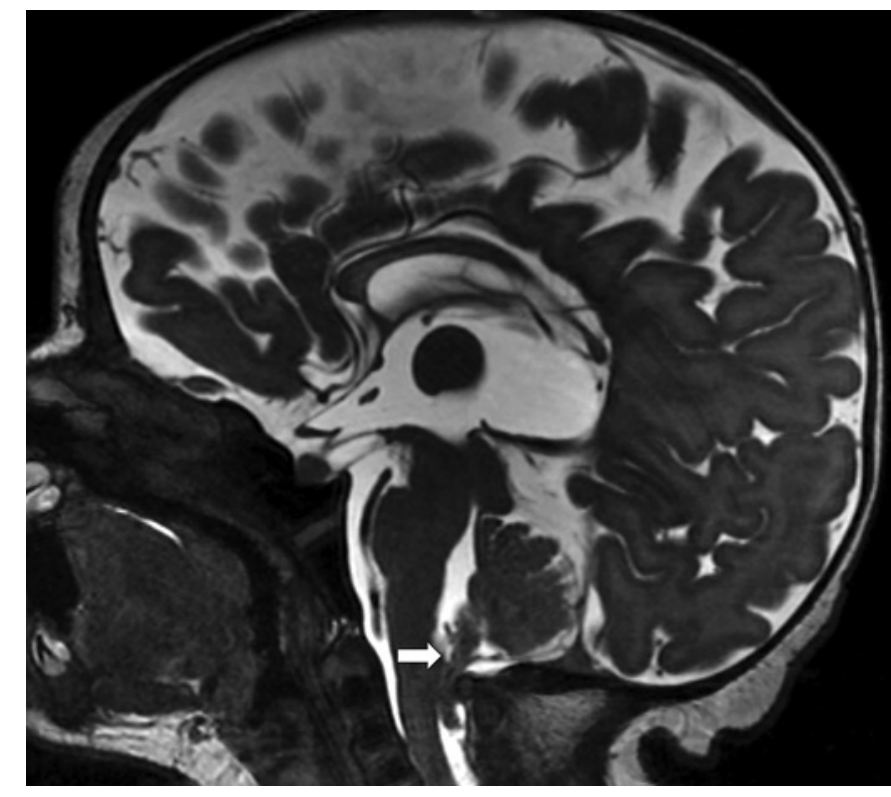

Fig. 2. Dysplastic vermian tissue (arrow is pointed to the dysplastic vermis; T2/FIESTA sagittal imaging).

Multiple linear regression models (OLS regression) were used to model the association of CC abnormalities, heterotopia binary and cerebellar defects on Bayley scores. Bayley scores were modeled with log-transformation in order to fulfill model assumptions. Additionally, the variables gestational age and gender were considered as confounders in the models.

All analyses were carried out with R, version 3.6.0 (April 26, 2019) (R Core Team (2019). R Markdown was used for dynamic reporting. The corresponding reporting guideline for observational studies is STROBE [31].

\section{Results}

\section{General}

Sixty-one patients were included in the analysis. One patient died on the first day of life due to severe lung hypoplasia (no follow-up data). Female/male ratio was 3:2. In utero, surgery was performed between $22+1$ and $26+$ 2 gestational weeks, mean $25+1$. Caesarean section was performed between $25+2$ and $37+3$ gestational weeks, and mean gestational age at birth was $35+4$ weeks. Prematurity, defined as birth before 37 gestational weeks, occurred in 28 patients (46.6\%): from these, 24 patients were late preterm $(85.7 \%), 3$ children were very preterm (10.7\%) and 1 girl was born extremely preterm (3.5\%; 25 +2 gestational weeks) due to an acute placental abruption during MMC repair, mandating emergency delivery. Birth weight ranged from 850 to $3,390 \mathrm{~g}$. 
Table 1. Imaging results and CSF diversion data

\begin{tabular}{lc}
\hline$N$ & $60(100)$ \\
CH II $(n, \%)$ & $60(100)$ \\
HH $(n, \%)$ & $4(6.7)$ \\
Abnormal CC $(n, \%)$ & $24(40)$ \\
Heterotopies $(n, \%)$ & $21(35)$ \\
Cerebellar defects $(n, \%)$ & $7(11.66)$ \\
Transverse cerebellar diameter, mean mm, range & $46.2(34-66)$ \\
Ventricular size, mean mm, range & $17.1(8.5-37.5)$ \\
Ventriculomegaly $(n, \%)$ & $58(96.66)$ \\
$\quad$ Mild & $22(36.66)$ \\
$\quad$ Moderate & $21(35)$ \\
$\quad$ Moderate severe & $9(15)$ \\
$\quad$ Severe & $5(8.33)$ \\
n/a & 1 \\
VPS/ETV $(n, \%)$ & $28(47)$ \\
VPS & $24(40)$ \\
ETV & $6(10)$ \\
$\quad$ ETV failure, secondary VPS & $2(3)$ \\
\hline
\end{tabular}

VPS, ventriculo-peritoneal shunt; ETV, endoscopic third ventriculostomy; CC, corpus callosum; $\mathrm{HH}$, hindbrain herniation; $\mathrm{CH}$ II, Chiari II malformation.

\section{Neonatal MRI}

On the first postnatal cranial MRI, CM II was present in all 60 patients (100\%). Normal position of the cerebellum was observed in 56 patients $(93.3 \%)$. HH was detected in 4 patients $(6.7 \%)$ with displacement ranging from $\mathrm{C} 1$ to $\mathrm{C} 4$ (in 1 patient to $\mathrm{C} 1$, in 2 to $\mathrm{C} 2$, and in 1 to C4). In 36 patients (60\%), the CC was completely normal while in 24 patients (40\%) a CC abnormality could be detected: 14 patients had a hypogenesis of the splenium, 9 patients showed a dysplastic CC, and 1 patient had CC agenesis.

Heterotopies were present in 21 patients (35\%). In 18 patients, they were subependymal, in 2 subependymal and cerebellar, and 1 patient had a single cerebellar heterotopia. The number of subependymal heterotopies ranged from 1 to 23 , mean 2.1 per patient.

Cerebellar parenchymal defects could be detected in 7 patients (12\%). Illustrative examples are shown in Figures 1 and 2. Transverse cerebellar diameter (maximum width in coronal MRI) ranged from 34 to $66 \mathrm{~mm}$, mean 46.2 $\mathrm{mm}$.

Neonatal ventricular size ranged from 8.5 to $37.5 \mathrm{~mm}$, mean $17.1 \mathrm{~mm}$. Mean FOHR was 0.5, with a range of $0.41-0.8$. Ventriculomegaly, defined as lateral ventricles larger than $10 \mathrm{~mm}$, was present in 58 (97\%) patients (details given in Table 1). When using the FOHR Index 51 $(85 \%)$, patients had a ventriculomegaly $(\mathrm{FOHR}>0.44)$.

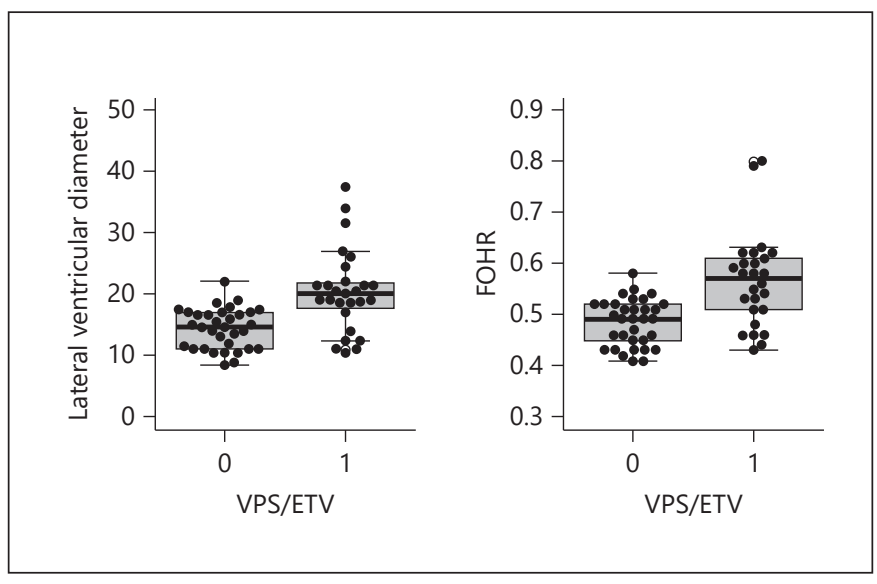

Fig. 3. Associations between lateral ventricular diameter and FOHR in patients with and without VPS/ETV (A 0 in the $x$-axis indicates children with neither VPS nor ETV, a 1 indicates children with either VPS or ETV or both). VPS, ventriculo-peritoneal shunt; ETV, endoscopic third ventriculostomy.

\section{Hydrocephalus and CSF Diversion}

In 32 patients (53\%), a CSF diversion was not necessary within the first 2 years of life. Due to ventriculomegaly and/or clinical signs of increased cerebral pressure, surgical intervention was necessary in $28(47 \%)$ patients 24 received a VPS, 20 within the first year, 4 within the second year. Six patients received a primary ETV. 2 patients of these needed a secondary VPS due to ETV failure (Table 1).

Width of the lateral ventricles and FOHR is correlated with VPS and ETV status (Fig. 3). The correlation shows that in patients with larger ventricles/larger FOHR, VPS/ETV was needed in a higher number of patients. In more detail, VPS/ETV patients had a mean of the lateral ventricles of $20.4 \mathrm{~mm}$ and a FOHR of 0.565 $(p<0.0001)$. Those who were not shunted had a mean of the lateral ventricles of $14.4 \mathrm{~mm}$ and a FOHR of 0.485 $(p<0.0001)$.

\section{Development}

The CCS was available for 55 (90\%) patients. Mean score was 93.6 (range 55-130, SD 14.3). LCS, tested in the same $55(90 \%)$ patients, yielded a mean of 89.7 (range $45-112$, SD 13.1). MCS was assessed in 48 (79\%) patients with a mean score of 77.4 (range 45-112, SD 13.0).

Additional brain malformations, namely CC abnormalities, heterotopies, and cerebellar defects, were not associated with any of the 3 Bayley Composite Scores. The comparison of children with 2 brain malformations to those without a malformation also showed no evidence 
Fig. 4. Associations between Bayley-III

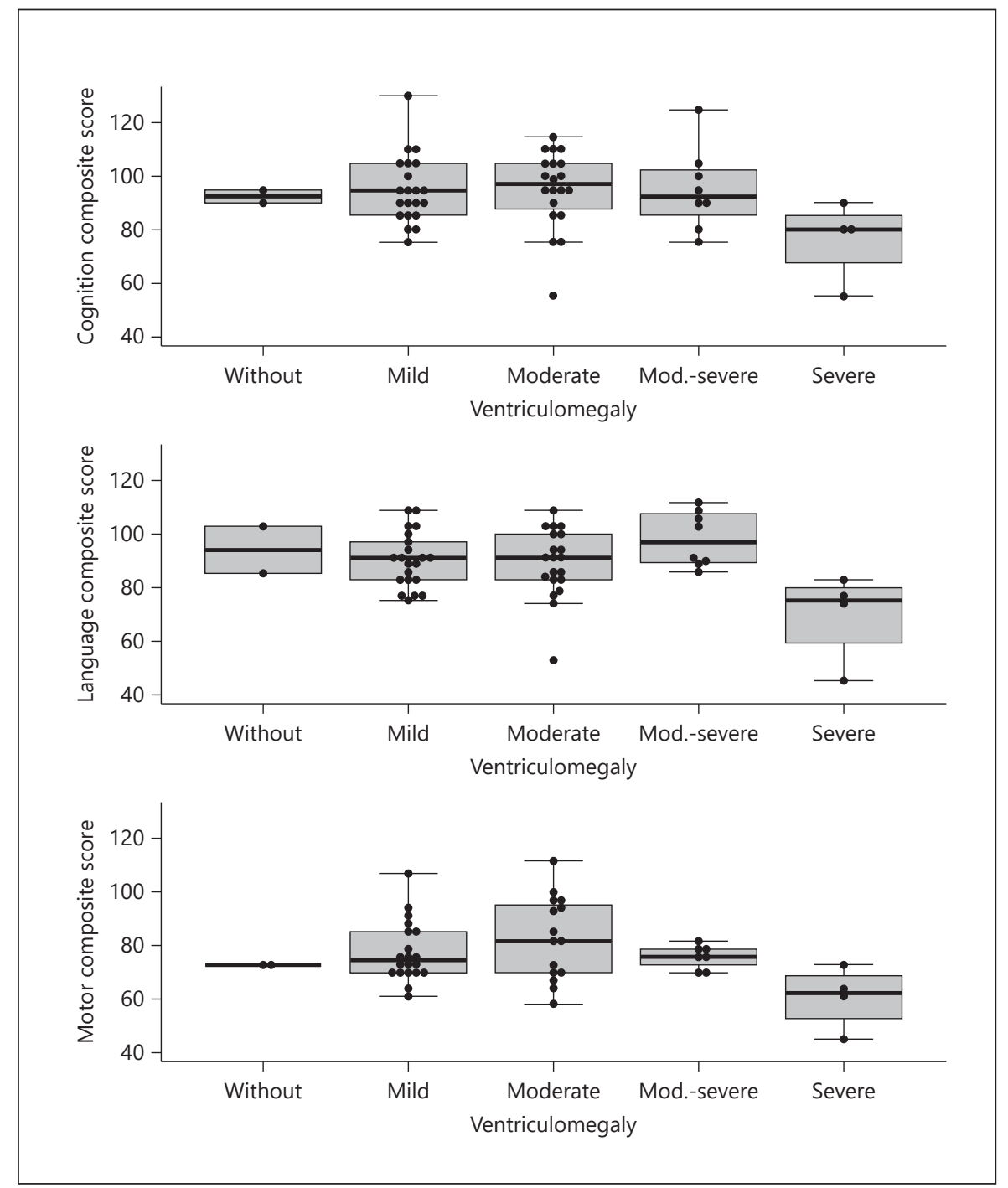
outcomes and ventriculomegaly.

for a between-group difference in the Bayley scores. In the 1 infant with all 3 additional malformations, no comparison was possible.

CCS, LCS, and MCS are related to the degree of ventriculomegaly (Fig. 4). Shortly, the group of children with severe ventriculomegaly had lower scores in all Bayley scores; however, only LCS was significant $(p<0.022)$. In children without ventriculomegaly and those with mild, moderate, and moderate-severe ventriculomegaly, no significant differences in the Bayley-III scores were detected. Confounding factors, as gender and gestational age, were adjusted, with no association between ventriculomegaly and Bayley outcomes.

In Figure 5, the association between patients with and without VPS/ETV and Bayley outcomes is illustrated. In brief, regarding CCS and LCS, there is no differ- ence within the 2 groups $(p<0.094$, respectively, $p<0.961$ ), whereas for the MCS, children with VPS/ ETV performed significantly worse than children without $(p<0.014)$.

\section{Discussion}

The Zurich Center for Fetal Diagnosis and Therapy (www.swissfetus.ch) and the Zurich Center for SB of the University Children's Hospital Zurich jointly represent one of the largest pediatric centers for SB patients worldwide. Due to a consistently high volume of prenatal surgery cases (actually 25-30 per year), the cohort of postnatal patients with a history of fetal SB repair is constantly growing. These patients are part of a com- 
Fig. 5. Associations between Bayley outcomes and VPS/ETV (A 0 in the $x$-axis indicates children with neither VPS nor ETV, a 1 indicates children with either VPS or ETV or both). VPS, ventriculo-peritoneal shunt; ETV, endoscopic third ventriculostomy.

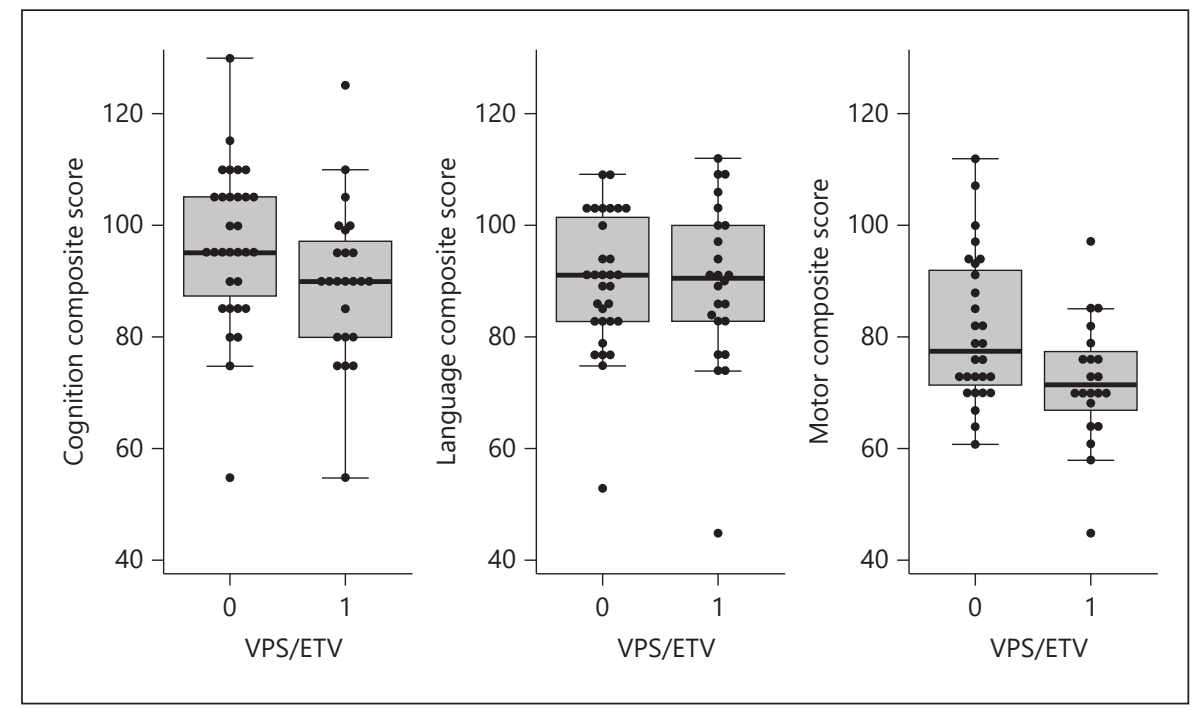

prehensive standard long-term follow-up program (birth - 18 years of age) with all pertinent data entered into a REDCap-based registry. To the best of our knowledge, this is the first study delivering comprehensive information on additional brain malformations and their impact on early developmental outcome in children after fetal SB repair.

Some of our results are novel, in particular the finding that additional brain malformations alone (i.e., $\mathrm{CC}$ abnormalities or heterotopies or cerebellar defects) or taken together do not seem to have an impact on any developmental domain when tested at 24 months of age. Other findings as severe ventriculomegaly, known to be a strong risk factor for poorer cognitive and language outcome, are corroborating previously published data $[12,32]$.

The following aspects deserve an in-depth discussion. Children in our cohort had cognition and language development in the low-average range compared to the population norm. These results are in line with the literature [28, 33, 34]. Reported IQ's of postnatally repaired SB patients are tendentially worse, that is, below the population average or in the low-average range with a heterogenous profile $[28,33,34]$. Yet, the MOMS trial demonstrated lower cognitive performance also for children with prenatally repaired SB at age 30 months [1]. Similar results could be shown in a review by Inversetti [24].

Of note, the current literature claims that primary brain malformations in SB patients deserve serious consideration regarding cognitive outcome. Accordingly, we closely examined 3 such additional cerebral malformations which may have had a negative impact on early life development. The key finding of this study is that neither CC abnormalities, heterotopies nor additional severe cerebellar defects alone or in combination of 2 or 3 , had an identifiable negative impact.

One other main finding was that severe ventriculomegaly had the highest predictive power regarding poorer developmental outcomes, although only language performance reached statistical significance. In children with a mild, moderate, and moderate-severe ventriculomegaly, no significant difference was detectable in all 3 Bayley scores compared to the group of children without ventriculomegaly. These results are comparable to the study by Lindquist, who demonstrated that children after postnatal surgery for SB without hydrocephalus performed better in all neuropsychological domains, with a total IQ of 103, compared to an IQ of 75 in SB children with hydrocephalus [35]. Interestingly, Houtrow [36] reported that children at 30 months of age with nonshunted hydrocephalus did not perform worse in neurodevelopmental testing than children with shunted hydrocephalus or children without hydrocephalus, yet children with severe hydrocephalus had lower scores. Our results are in line with these findings. Only children with a neonatal ventriculomegaly larger than $25 \mathrm{~mm}$ had worse Bayley scores. MOMS data suggested that larger lateral ventricular size at initial prenatal imaging was associated with an increased need for shunting [1]. This seems especially true in patients with a fetal ventricular size larger than $15 \mathrm{~mm}$ $[37,38]$. In our cohort, VPS and ETV placement was necessary in patients up to the age of 2 years with a mean neonatal ventricular size of $20.4 \mathrm{~mm}$ and a mean neonatal FOHR of 0.565 . 
For children with and without VPS/ETV, Bayley testing was different only in the MCS, with a significantly lower score in the group of shunted children with severe ventriculomegaly. In the CCS and LCS, a significant difference between the 2 groups was not found, with between-group estimates in the CCS of 6.5 and in the LCS of 0.18 . VPS/ETV on its own did not appear to have a negative impact on cognition, but on motor function when tested at the age of 2 years.

Our study cannot answer the interesting question whether the poorer cognitive performance is due to hydrocephalus or the structural changes leading to it, or, eventually, both. Briefly summarized, our data suggest that low-average IQ Bayley scores result from the typical primary brain malformations in SB, while the corresponding hydrocephalus adds an additional negative impact, especially if severe.

We have already published that a classical $\mathrm{HH}$ was present in $90 \%$ of fetuses before fetal surgery and that it resolved in utero in $90 \%$ of these within 4 weeks postoperatively [11]. As to be expected, in our postnatal population, $\mathrm{HH}$ was absent in $93.3 \%$ while MOMS reported only $36 \%$ of reversed HHs [1]. We have speculated about possible explanations for that striking difference (different definitions, MRI evaluations, or operative technique), but none of these is convincing. For children with cerebellar dysplasia/low cerebellar volume, testing of fine motor function should be a focus of future investigations. It will be interesting to investigate the effect of brain malformations on cognition when detailed assessment of executive functions is included in cognitive testing, for example, at 5 and 10 years of age. Definitely, our study underscores the necessity of prenatal counseling regarding brain malformations and ventriculomegaly and their possible impact on outcomes.

Limitations of our study include that results were not compared to SB children after postnatal surgery. Also, due to strict eligibility criteria, our cohort harbors a selection bias (potentially "healthier" patients). In fact, fetuses exhibiting, for instance, severe other malformations or genetic syndromes, were excluded. Finally, due to the patient's young age, we cannot yet present potentially revealing long-term outcome data on more specific cognitive testing (i.e., executive functions and visual perception).

In summary, this study produces evidence that additional structural brain malformations, namely CC anomalies, heterotopies, and cerebellar defects, identified in neonates with a history of fetal surgery for SB, did not negatively impact developmental outcomes at 2 years of age. We demonstrate further that, in contrast, severe neonatal ventriculomegaly is a strong risk factor for poorer development. The cohort of patients reported on here will be followed in an already designed longitudinal study in order to look at specific cognitive skills, especially executive functions in the years to come.

\section{Acknowledgements}

We would like to thank all the participating families from the Pediatric SB Center of the University Children's Hospital Zurich.

\section{Statement of Ethics}

This research complies with the guidelines of human studies and was conducted ethically in accordance with the World Medical Association Declaration of Helsinki. The study was approved by the local Ethics Committee (KEK-ZH No. 2015-0172). Subjects (or their parents or guardians) gave their written informed consent before participating in the study and publication of the results.

\section{Conflict of Interest Statement}

The authors declare no conflicts of interest. Prof. Meuli is an Associate Editor of the Journal "Fetal Diagnosis and Therapy."

\section{Funding Sources}

We thank the Uniscientia and the Zwillenberg Foundations as well as the Meili and Roesle Families for financial support and their interest in our work.

\section{Author Contributions}

Each author meets all criteria for authorship corresponding to the ICMJE (International Committee of Medical Journal Editors) and has made the following jobs: (1) Substantial contributions to the conception or design of the work; or the acquisition, analysis, or interpretation of data for the work. (2) Drafting the work or revising it critically for important intellectual content. (3) Final approval of the version to be published. (4) Agreement to be accountable for all aspects of the work in ensuring that questions related to the accuracy or integrity of any part of the work are appropriately investigated and resolved.

\section{Data Availability Statement}

All data generated or analyzed during this study are included in this article. Further enquiries can be directed to the corresponding author. 


\section{References}

1 Adzick NS, Thom EA, Spong CY, Brock JW 3rd, Burrows PK, Johnson MP, et al. A randomized trial of prenatal versus postnatal repair of myelomeningocele. $\mathrm{N}$ Engl J Med. 2011;364(11):993-1004.

2 Hino-Shishikura A, Niwa T, Aida N, Okabe T, Nagaoka T, Shibasaki J. Periventricular nodular heterotopia is related to severity of the hindbrain deformity in Chiari II malformation. Pediatr Radiol. 2012;42(10):1212-7.

3 Fletcher JM, Copeland K, Frederick JA, Blaser SE, Kramer LA, Northrup H, et al. Spinal lesion level in spina bifida: a source of neural and cognitive heterogeneity. J Neurosurg. 2005;102(3 Suppl 1):268-79.

4 D'Antonio F, Pagani G, Familiari A, Khalil A, Sagies TL, Malinger G, et al. Outcomes associated with isolated agenesis of the corpus callosum: a meta-analysis. Pediatrics. 2016 138(3):e20160445.

5 Just M, Schwarz M, Ludwig B, Ermert J, Thelen M. Cerebral and spinal MR-findings in patients with postrepair myelomeningocele. Pediatr Radiol. 1990;20(4):262-6.

6 Stevenson KL. Chiari Type II malformation: past, present, and future. Neurosurg Focus. 2004;16(2):E5.

7 Cama A, Tortori-Donati P, Piatelli GL, Fondelli MP, Andreussi L. Chiari complex in children-neuroradiological diagnosis, neurosurgical treatment and proposal of a new classification (312 cases). Eur J Pediatr Surg. 1995 5(Suppl 1):35

8 Geerdink N, van der Vliet T, Rotteveel JJ, Feuth T, Roeleveld N, Mullaart RA. Essential features of Chiari II malformation in MR imaging: an interobserver reliability study-part 1. Childs Nerv Syst. 2012;28(7):977-85.

9 McLone DG, Dias MS. The chiari II malformation: cause and impact. Childs Nerv Syst. 2003;19(7-8):540-50.

10 Miller E, Widjaja E, Blaser S, Dennis M, Raybaud $C$. The old and the new: supratentorial MR findings in Chiari II malformation. Childs Nerv Syst. 2008;24(5):563-75.

11 Moehrlen U, Ochsenbein N, Vonzun L, Mazzone L, Horst M, Schauer S, et al. Fetal surgery for spina bifida in Zurich: results from 150 cases. Pediatr Surg Int. 2021.

12 Iddon JL, Morgan DJ, Loveday C, Sahakian BJ, Pickard JD. Neuropsychological profile of young adults with spina bifida with or without hydrocephalus. J Neurol Neurosurg Psychiatry. 2004;75(8):1112-8.

13 Heffez DS, Aryanpur J, Hutchins GM, Freeman JM. The paralysis associated with myelomeningocele: clinical and experimental data implicating a preventable spinal cord injury. Neurosurgery. 1990;26(6):987-92.
14 Hutchins GM, Meuli M, Meuli-Simmen C, Jordan MA, Heffez DS, Blakemore KJ. Acquired spinal cord injury in human fetuses with myelomeningocele. Pediatr Pathol Lab Med. 1996 Sep;16(5):701-12.

15 Meuli M, Meuli-Simmen C, Hutchins GM, Seller MJ, Harrison MR, Adzick NS. The spinal cord lesion in human fetuses with myelomeningocele: implications for fetal surgery. J Pediatr Surg. 1997;32(3):448-52.

16 Meuli M, Meuli-Simmen C, Yingling CD, Hutchins GM, Hoffman KM, Harrison MR, et al. Creation of myelomeningocele in utero: a model of functional damage from spinal cord exposure in fetal sheep. J Pediatr Surg. 1995; 30(7):1028-3

17 Meuli M, Meuli-Simmen C, Yingling CD, Hutchins GM, Timmel GB, Harrison MR, et al. In utero repair of experimental myelomeningocele saves neurological function at birth. J Pediatr Surg. 1996;31(3):397-402.

18 Meuli M, Meuli-Simmen C, Hutchins GM, Yingling CD, Hoffman KM, Harrison MR, et al. In utero surgery rescues neurological function at birth in sheep with spina bifida. Nat Med. 1995;1(4):342-7.

19 Stiefel D, Copp AJ, Meuli M. Fetal spina bifida in a mouse model: loss of neural function in utero. J Neurosurg. 2007;106(3 Suppl 1):21321.

20 Stiefel D, Meuli M. Scanning electron microscopy of fetal murine myelomeningocele reveals growth and development of the spinal cord in early gestation and neural tissue destruction around birth. J Pediatr Surg. 2007; 42(9):1561-5

21 Adzick NS, Sutton LN, Crombleholme TM, Flake AW. Successful fetal surgery for spina bifida. Lancet. 1998;352(9141):1675-6.

22 Sutton LN, Adzick NS, Bilaniuk LT, Johnson MP, Crombleholme TM, Flake AW. Improvement in hindbrain herniation demonstrated by serial fetal magnetic resonance imaging following fetal surgery for myelomeningocele. JAMA. 1999;282(19):1826-31.

23 Bruner JP, Tulipan N, Paschall RL, Boehm FH, Walsh WF, Silva SR, et al. Fetal surgery for myelomeningocele and the incidence of shunt-dependent hydrocephalus. JAMA. 1999;282(19):1819-25.

24 Inversetti A, Van der Veeken L, Thompson D, Jansen K, Van Calenbergh F, Joyeux L, et al. Neurodevelopmental outcome of children with spina bifida aperta repaired prenatally versus postnatally: systematic review and meta-analysis. Ultrasound Obstet Gynecol. 2019; 53(3):293-301.

25 Meuli M, Moehrlen U, Flake A, Ochsenbein N, Huesler M, Biro P, et al. Fetal surgery in Zurich: key features of our first open in utero repair of myelomeningocele. Eur J Pediatr Surg. 2013;23(6):494-8.
26 Mohrlen U, Ochsenbein-Kolble N, Mazzone L, Kraehenmann F, Husler M, Casanova B, et al. Benchmarking against the MOMS trial: Zurich results of open fetal surgery for spina Bifida. Fetal Diagn Ther. 2019:1-7.

27 Barkovich AJ. Pediatric Neuroimaging. Philadelphia: Wolters Kluwer; 2019.

28 Johnson MP, Gerdes M, Rintoul N, Pasquariello P, Melchionni J, Sutton LN, et al. Maternal-fetal surgery for myelomeningocele: neurodevelopmental outcomes at 2 years of age. Am J Obstet Gynecol. 2006;194(4):1145-2.

29 O'Hayon BB, Drake JM, Ossip MG, Tuli S, Clarke M. Frontal and occipital horn ratio: a linear estimate of ventricular size for multiple imaging modalities in pediatric hydrocephalus. Pediatr Neurosurg. 1998;29(5):245-9.

30 Bayley N. Bayley Scales of Infant and Toddler Development. 3rd ed: Harcourt Assessment Inc.; 2015.

31 von Elm E, Altman DG, Egger M, Pocock SJ, Gøtzsche PC, Vandenbroucke JP, et al. The strengthening the reporting of observational studies in epidemiology (STROBE) statement: guidelines for reporting observational studies. Lancet. 2007;370(9596):1453-7.

32 Weichert J, Hartge D, Krapp M, Germer U, Gembruch U, Axt-Fliedner R. Prevalence, characteristics and perinatal outcome of fetal ventriculomegaly in 29,000 pregnancies followed at a single institution. Fetal Diagn Ther. 2010;27(3):142-8.

33 Wills KE, Holmbeck GN, Dillon K, McLone DG. Intelligence and achievement in children with myelomeningocele. J Pediatr Psychol. 1990;15(2):161-76.

34 Friedrich WN, Lovejoy MC, Shaffer J, Shurtleff DB, Beilke RL. Cognitive abilities and achievement status of children with myelomeningocele: a contemporary sample. J Pediatr Psychol. 1991;16(4):423-8.

35 Lindquist B, Uvebrant P, Rehn E, Carlsson G. Cognitive functions in children with myelomeningocele without hydrocephalus. Childs Nerv Syst. 2009;25(8):969-75.

36 Houtrow AJ, Burrows PK, Thom EA. Comparing neurodevelopmental outcomes at 30 months by presence of hydrocephalus and shunt status among children enrolled in the MOMS trial. J Pediatr Rehabil Med. 2018; 11(4):227-35.

37 Tulipan N, Wellons JC 3rd, Thom EA, Gupta N, Sutton LN, Burrows PK, et al. Prenatal surgery for myelomeningocele and the need for cerebrospinal fluid shunt placement. J Neurosurg Pediatr. 2015;16(6):613-20.

38 Vonzun L, Winder FM, Meuli M, Moehrlen U, Mazzone L, Kraehenmann F, et al. Hindbrain herniation and banana and lemon sign after open fetal myelomeningocele repair when do these signs disappear and is shunting predictable? Ultraschall Med. 2020. 